\title{
Industry-Academia Linkages in a High Tech Research Field
}

\author{
Sercan Ozcan ${ }^{1}$, Nazrul Islam ${ }^{2}$ \\ 1Faculty of Engineering and Natural Sciences, Bahçeşehir University, Istanbul, Turkey \\ ${ }^{2}$ Dundee Business School, University of Abertay Dundee, Dundee, DD1 1HG, Scotland, U.K.
}

\begin{abstract}
Currently academic researches' focus started changing towards protecting IP rights and to transferring them into industrial actors. Accordingly, it is argued that academic's basic research focus started shifting towards applied research as it is essential for the radical inventions to be introduced in a competitive market. This research seeks to understand industry-academia linkages in a high tech field such as nanocrystals. In regards to supporting the technology transfer process within or cross country, this study illustrates the technology development trends and actors' engagement; nano-crystals technology and their interconnections; and maps the organisational (industry-academia) linkages that enhance the commercialisation of radical inventions. The results show that the industry-academia linkages that appeared as decentralized structure are more stable compared to other linkage types. Korean and Japanese organisations present such stable linkages. The linkages are even stronger when they appear as a monolinkage. Chinese organisations show a great illustration of such an effective mono-linkage of high tech coinventorships. The organisations in the US maintain international linkages.
\end{abstract}

\section{INTRODUCTION}

Nanotechnology is not confined to one particular industry; rather it offers an enabling set of technologies that cross all industry sectors and science \& engineering disciplines. There are currently various nanotechnology goods and materials exist at the production and commercial level; however, it is still a growing area and is considered to be an emerging technology field [1-4]. Even though there are high numbers of nanotechnology patents available, commercialised products utilising the technology are very limited in number [5]. Currently, the public research organisations have increased the commercialisation activities of new inventions as there is much publicly funded research being introduced to the market [6-8]. Considering the obvious benefits of patenting activities, governments are making considerable efforts to support academic and corporate organisations with funds in view of the long-term relationship between technology and the economy [9]. Also, governments are trying to introduce a patent authorization system that makes patented technology more readily available to ensure other interested companies have access to basic inventions [10].

Academic actors play a key role in the patent generation process, as nowadays they frequently collaborate with large corporate players and are fully or partly supported by public funds [11]. The increase of academic patent generation significantly supports the technology diffusion process because the core notion underpinning technology transfer from universities is the commercialisation of research results $[12,13]$. Some governments are aiming to motivate academic organisations by transferring patent ownership from the government to academic organizations, which eases the technology transfer process by increasing legal certainty and reducing transaction costs [14]. Growing interrelationships amongst countries in the context of linkage have fostered the usage and implementation of patents with the purpose of ensuring funds are invested in innovation and increase the dissemination of technology [15]. In a specific country, the key actors who play a central role in the technology diffusion process may be different. The linkage between key actors in one research domain may vary to that of another and these different linkages may lead to more or less productive innovation systems. It can be assumed that the role of dominant actors may differ from country to country as countries' technology transfer processes may be driven by government initiatives, by public institutions, and some may be driven by private companies. To analyse patenting activities with a particular focus on a specific technology would be one way to see which settings of the innovation process are more productive and so improve the effectiveness of patenting systems and the diffusion of new inventions. 
Patents are regarded as an intersection between inventions and innovations leading to the diffusion of technology [16]. There are plenty of patent studies that focus on the association amongst technological advancement and economic progression [17-20]. Some studies focus on the research and innovation developments in a countrywide and a global context [21-24]. There is some researched that concentrated on the viewpoint of corporations strategy to assess the stage of technology development in a particular sector by analysing patent statistics as a guide or a certain technology [25-28]. It is comprehended that our study differs from the existing studies, as this work concerns the types of organisational linkages by examining patent coownership rather than citation linkages. The patent co-ownership analysis is a better model for this study as it is possible to capture actual collaborative linkage between industry and academia, while citation analysis is a more appropriate method for presenting knowledge flow between actors. Moreover, focusing on type of linkages introduces different level of analysis in these kinds of patent studies and this could introduce different outcomes for technology management specialists and patent analysts.

\section{ANALYTICAL FRAMEWORK}

Patenting activity appears to be one of the crucial elements in the increasingly interlinked participations between various academic and corporate organisations to block the competitors and benefit from their investments in $\mathrm{R} \& \mathrm{D}$. Currently companies follow various patenting strategies such as collaborative patenting techniques to avoid imitations and to protect their own technology by keeping competitors away from their invention. As the number of competitors increased due to globalisation, mainly innovative and R\&D-reliant companies demand for higher intellectual property (IP) protection. IP rights are even more essential to new technology-based firms such as spin-offs as these firms usually have very limited assets and they need to be able to protect their core technology or process to hold on to their business. Only a secure IP right eases the process of participating innovation network. As such current patenting strategies promote collaboration with other organisations to involve in the same industry as even large corporations find it difficult sustain their technology.

Academic patenting strategies are different in nature compared to the industrial approach due to many reasons such as research aim, the source of fund and timescale of research. Nowadays, fund providers are looking for research applications that are aimed at commercialisation and partnership of an at least one academic and industrial player within the same project. Industrial organisations mainly fund academia if they see a direct benefit to their field such as commercialization of a product or making their current process more efficient. Currently academic patenting approach started changing towards protecting IP rights and transferring them to industrial players. Accordingly, it is argued that the basic research started shifting towards applied research and that basic research is highly essential for those radical innovations to be introduced. Current researches show that this new academic patenting approach resulted in significant increase for universities to follow applied research more than before. However, patenting started becoming a priority compared to publications as in countries like China where government encourages academia to patent an invention beforehand of a publication. In general, the trend of academic involvement in patenting activities is changing and thus the linkages between academia and industry have gained even more importance than before. As a result, the efficiency of linkage between academia and industry is highly essential for the smooth functioning of systems of innovation (SI) [29-36].

Corporations are mainly looking for short-term possible commercialization opportunities as they work at highly different time-scale. On the other side, academia works at different timescale as researches are in a wider term. Even though there is a changing trend, corporations highly focus on applied research and academia follows fundamental research and as usual it is always difficult for academia to identify industrial problems. Accordingly, there are many disputes exist between academia and industry linkages. This becomes even more complicated when it comes to a field such as nanotechnology which is highly dispersed into different fields 
and requires critical mass of expertise from these research fields. Moreover, industrial actors have difficulties to access to right information as it is highly complicated due to lack of hybrid expertise that can bridge academia and industry. To fill in the gap between academia and industry, there are various procedures seem to be effective. Some of them are shared funds such as Seventh Framework Programme (FP7), Nano KTN (Knowledge Transfer Network). These types of funds are highly linked to academia-industry funds and that it encourages many organisations to have different roles within a project. Intermediaries also take an important role in these kinds of projects so that the research is all linked between different parties to increase the success rate of results. What is more, collaboration between academia and industry is highly globalized. Involvement of larger number of international and diverse actors have increased the number of collaborative patenting activities that have assisted owners of patents to have appropriate and faster returns from their research.

Large involvement of various types of actors and gloablisation of research lead to complexity to explore clusters and linkages within a particular sector. Especially it is even more complicated when an emerging and a hybrid field is considered. Nanotechnology can be classified as a science-based cluster [37] which is highly R\&D-and patent-focused and is likely to have a close relationship with the public research sector (i.e. universities, government research bodies etc.). This is due to their requirement for basic research and so it is essential for the public research sector to become involved for there to be an effective innovation structure. To understand insights of linkages within a network, there are different researches and theories are followed, for example the triple helix model, the Techno-Economic Network (TEN) model, and network models. These different models are examined to gain information about the structure or types of linkages within an SI. The Triple Helix concept comprises a model for collaborative relationships between three major institutional spheres that comprise universities, industry and government. This model presents manifold mutual relationships at various stages of the knowledge capitalization process [38]. There are three main different actors within this model and these actors may or may not be linked effectively in terms of patenting activities. Through patent analysis, it may not be possible to see the linkages between government and other actors, as the fund providers cannot be identified through patent analysis. However, this model can be used to understand insights of interactions between two spheres, which are academia and industry. Another model that illustrates the roles and linkages of actors within an innovation system is the TEN model [39], a useful framework to analyse the systems of innovation in a comprehensive manner for a chosen sector. The TEN model has been organised around three major poles that are Technology, Science, and Market. Another minor pole that is presented within this system is the Finance pole, due to its indirect players or innovation links. Each of these poles is categorised by the type of actors and intermediaries in regard to their duties. Intermediaries vary in terms of tangible and intangible resources for those actors within TEN. Following this model it should be possible to identify various linkage mechanisms within a system. Even though the TEN model and the triple helix model illustrate actors and their linkages, these models do not identify linkage mechanisms in regard to types and formation of networks.

Having examined different models, the network structures of these linkages should be analysed as well. One can assume there would be academic and industrial linkages in nanocrystal patenting activities, but it is not clear if the form of linkages consists of small clusters or a network on a larger geographical scale. One of the basic categorisations of networks describes them as centralised, decentralised, or distributed [40]. Accordingly, there can be a network with a dominant central ego to which other nodes are directly linked. This network may not have a very healthy structure as the network is controlled by an individual organisation and the progress of the network may be slow and unstable. The structure of a network is likely to be vulnerable and unstable if there is a single node in it, as it is too dependent on the central ego. A decentralised network can be considered as a more efficient model in terms of knowledge flow compared to the centralised model, as the structure consists of clusters or smaller networks with a higher number of central organisations. The most effective and stable network structure is the distributed network, as risk factors are lower compared to other types of networks. Distributed networks are likely to have lower levels of 
formalised interactions among comparatively equal organisations and the distribution of knowledge and resources will be more balanced. Considering previous models, the following linkage model in Figure 1 is being proposed as an analytical framework for this study. The core idea of this paper is to analyse the network structure and linkage mechanism of this particular high tech research field. However, it is assumed that there will be various structures where there are central players or multiple dominant actors appearing within nanocrystal SI networks. The proposed model consists of five different network linkage types, which for the purposes of this study have been termed: mono-linkage, oligo-linkage, central-linkage, decentral-linkage and distributed linkage (see Figure 1). Considering the triple helix and TEN models, it is expected that there will be various types of linkages in terms of actors and information flow. For example, a mono-linkage might exist between an academic and an industrial player where the information flow is between the Science and the Market poles.

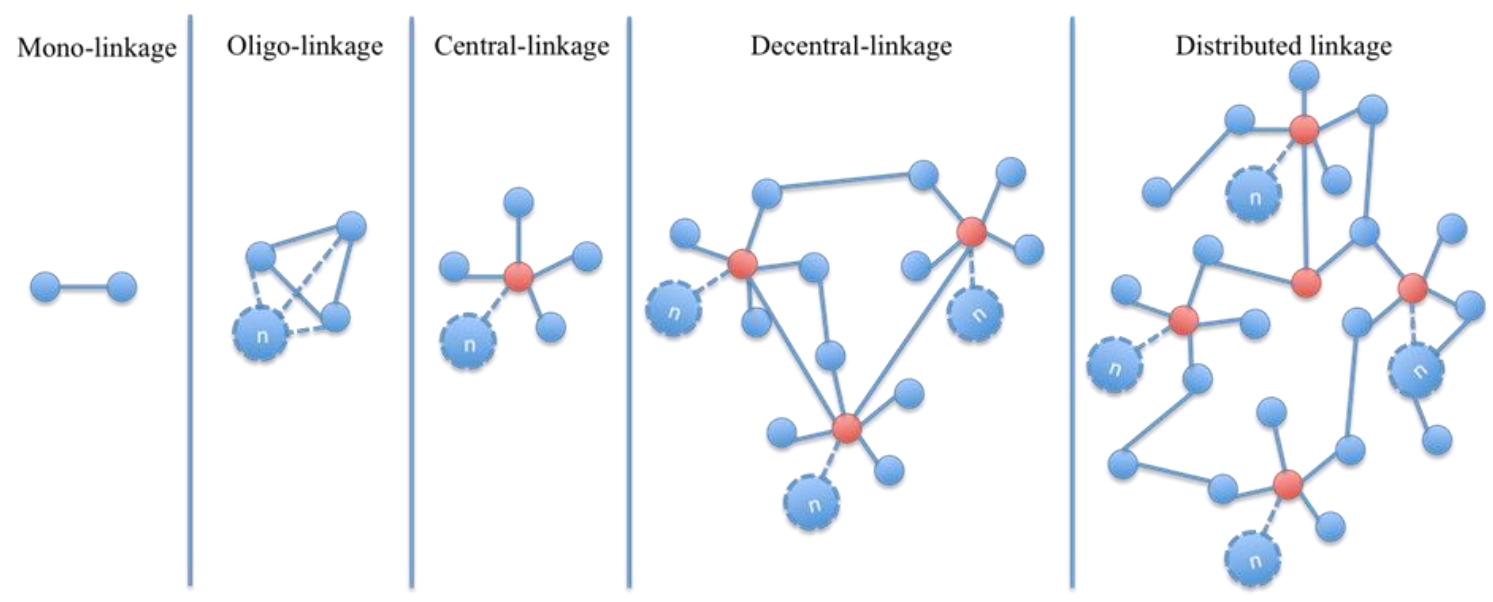

Figure 1: Proposed model of patenting linkages

This study will apply the proposed model to analyse the nanocrystal case, where the industry-academia linkage of nanocrystal technology will be examined in terms of the structure by which organisations are linked to each other and what the national differences are with regard to the various network types as previously described (i.e. mono-linkage, oligo-linkage, central-linkage, decentral-linkage and distributed linkage), and what the network characteristics are for nanocrystal technology. To fulfill the purpose of the study, it attempts to answer the following fundamental questions: 1) what the current network structures are in terms of the linkages between industry and academia; 2) how industry and academia actors are linked to each other and how effective their linkage is.

\section{DATA AND RESEARCH METHOD}

Considering the majority of quantitative methods in business and management studies, patent data mining studies are less frequent and it is still a developing field. Moreover, a high tech research field such as nano-crystals technology was emerged in the beginning of this millennium so this is an important area to work on. This research applies a tech-mining method, expounded by Porter and Cunningham [41], which has had a significant impact on the analysis of technology dynamics. Tech- mining can be used to determine actors engagement and technology linkage within a given innovation system. Patent data for this study have been retrieved from the Thomson Innovation database which has a significant number of patent authority coverage compared to Delphion and MicroPatent that provide a limited number of patent authorities. The data was analysed using tech mining software Thomson Data Analyser (TDA), which automates mining and clustering of terms occurring in patent abstracts and descriptors as according to authors, affiliations or keywords that it recommends. This makes 
the results increasingly valid and reliable; as this data mining software allowed the data to be cleaned further to eliminate unnecessary patent documents and duplicates. For the nano-crystal case, the following search terms were used:

$(\mathrm{AIOE}=(\mathrm{B} 82 *)$ OR $\mathrm{FIC}=(\mathrm{B} 82 *)$ OR $\mathrm{UCC}=(977 *))$ AND $\left(\mathrm{ALLD}=\left(\right.\right.$ nanocrystal* ${ }^{*}$ or nano-

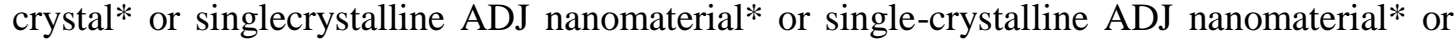
crystalline ADJ nanoparticle* or quantum ADJ $\left.\operatorname{dot}^{*}\right)$ )

After collecting the patent dataset, there were still certain steps exist that need to be taken to optimise the data set. However, duplicates are very rare in the data since DWPI is used in the patent data collection phase. For those remaining irrelevant documents, TDA was used to eliminate them and to achieve the required results. After optimizing the data set, Themescape tool was used to extract text terms from a set of patent records and to generate a topological map showing the frequency of a term's occurrence as apparent peaks on a geographical island. This was best done by analysing a set of patent families, which required a search of the Derwent database records, restricting the search to a single country and document type, or sub-searching within the map. By using Themescape, we mapped the key technologies for all available nanocrystal patents. The analysis of a Themescape map was important for the findings of this study because it allowed the categorisation of documents containing similar content, as they were placed near each other on the map. Moreover, the density of documents can be indicated with tall or small peaks and the distance between peaks sheds light on the relationship between content, as peaks that are located closer to each other have more closely related content than peaks that are located farther away. Contour lines indicate relative document density and by using the tool it is possible to zoom in on a specific area whereby new contours, labels, and documents can be revealed.

As a result, 1954 individual nanocrystal-related patents were obtained after optimisation for the period of 1970-2012. The optimised data were imported into TDA to validate the results further. Duplicate results were eliminated and variations of company, inventor, institutes and university names were unified where they appeared as separate patent assignees. After the dataset was cleaned and prepared, various functions offered by TDA were utilised to generate the required analysis. The outline of research design is shown in Table 1.

Table 1: The outline of research design

\begin{tabular}{|c|c|}
\hline $\begin{array}{l}\text { Patent database } \\
\text { selection }\end{array}$ & $\begin{array}{ll}\text { - } & \text { Searching for available patent database providers } \\
\text { - } & \text { Comparison of patent databases (taxonomical study) } \\
\text { Selecting the right patent database provider }\end{array}$ \\
\hline $\begin{array}{l}\text { Patent search } \\
\text { process }\end{array}$ & $\begin{array}{l}\text { - } \\
\text { - } \\
\text { - } \\
\text { Examinasinating duplicates by obtaining patent data with DWPI } \\
\text { Exporting data to TDA with TDA format }\end{array}$ \\
\hline $\begin{array}{l}\text { Patent data } \\
\text { optimization }\end{array}$ & $\begin{array}{ll}\text { - } & \text { Loading required fields of patent data to TDA } \\
\text { - } & \text { Filtering results to eliminate duplicates } \\
\text { Preparing categories and groups for analysis }\end{array}$ \\
\hline $\begin{array}{l}\text { Patent data } \\
\text { analysis }\end{array}$ & $\begin{array}{l}\text { - Analysis of nanocrystal patent data by topological mapping } \\
\text { - Analysis of industry-academia linkages in nanocrystals }\end{array}$ \\
\hline $\begin{array}{l}\text { Interpretation and } \\
\text { conclusion }\end{array}$ & $\begin{array}{l}\text { - Interpreting the patent analysis of technology linkages } \\
\text { - Discussion, Implications and Recommendations }\end{array}$ \\
\hline
\end{tabular}

\section{RESULTS}

Nano-crystals (NCs) are nanomaterials that have wide usage in chemistry, electronic and optoelectronic applications. Some companies have started to commercialise products using 
NCs and this is one of the nanomaterials that have advantages over some other nanomaterials and nanocomposites. NCs are predicted to lead to radical innovations in terms of a bottom-up approach in that they will make manufacturing processes more efficient, and a top-down approach in view of their flexible nature, and their excellent electronic and optoelectronic characteristics. NCs have different characteristics depending on their shape and dimensions, composition and size. Some of these characteristics include great luminescence efficiency, low thermal conductivity and tunable electronic structures combined with small exciton binding energy. These characteristics make NCs exceptionally appealing for field-effect transistors, solar cells, memory devices, various display/lighting technologies, laser applications and sensors. The quantum tenability of NCs and their various characteristics have resulted in with many successful prototype devices, raising the interest of many large companies in becoming involved in these new NCs. Consequently, many organizations have started investing in this technology and have applied for patents.

\section{Patenting trends in a high tech research field (Nano-crystals)}

As mentioned 1954 patents had been granted for NCs technology by April 2012. The first NCs patent was granted in 1987 (see Figure 2). Now, there are 4338 inventors, 2340 organizations and 30 countries are involved in NCs technology. The significant increase in the number of NCs related patents started from 2000 and the peak for patenting activity was between 2004 and 2008. The gradual increase in patent documents promises the high commercialisability of this technology, and the number of NCs patents are higher than those granted for its competitive material, nanocomposites (1792 patents), but it falls behind other nanotechnology related materials such as nanotubes (11661) and nanowires (4484).

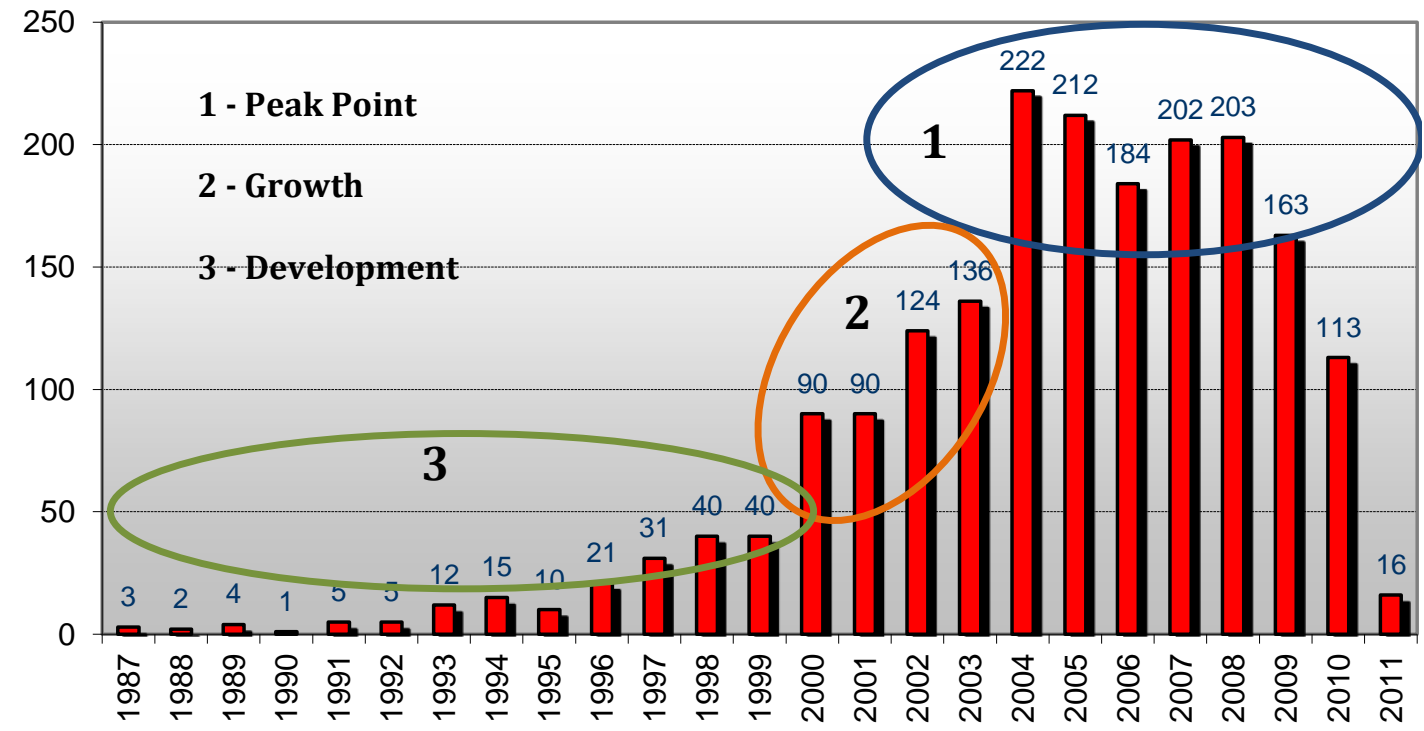

Figure 2: Patenting trends in Nano-crystals technology field

In Table 2, country profiles with regard to the leading organizations within that country can be seen. The Korean based multi-national company Samsung is the leading organization within the US and Korea. This is due to the fact that Samsung often patents its inventions both in the US and Korea at the same time. From this table it can be seen that academic organizations within the US play a key role in NCs patenting activity and help ensure the US's leading position. As a matter of fact, academic organizations in every top NCs countries perform an important function, for instance, China's top three players are all universities. The statistics of the percentage of granted patents within the last three years supports the changing rank of China as $67 \%$ of their NCs patents have been granted within the last three years, which is the highest number compared to other countries. The second rapid increase has taken place in Russia with $36 \%$ and the third country is Korea with a $16 \%$ increase. Another important point that is 
captured is that, except for the US and Korea, between all other nations there is great variance in terms of where NCs inventions are patented under what patent classifications. This is due to the possible application of NCs in different fields and these possible fields will be explained in the following section.

Table 2: Country profile of Nano-crystals technology field

\begin{tabular}{|c|c|c|c|c|c|}
\hline$\stackrel{\partial}{\not}$ & t & 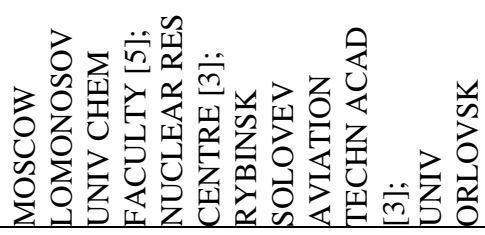 & 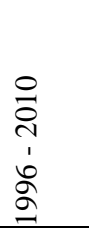 & 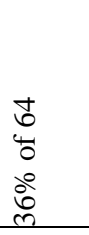 & 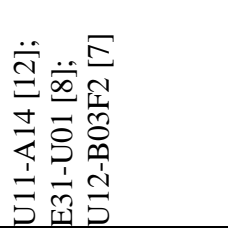 \\
\hline 됨 & $\bar{a}$ & 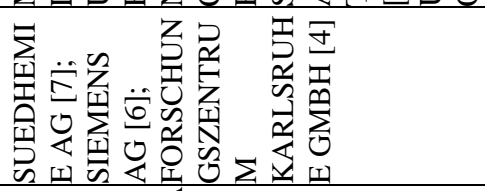 & $\begin{array}{l}0 \\
\stackrel{1}{1} \\
1 \\
1 \\
\infty \\
2 \\
\end{array}$ & 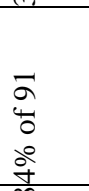 & 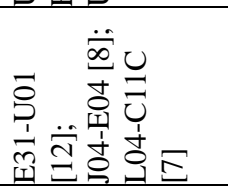 \\
\hline 乙 & $\stackrel{\infty}{\subseteq}$ & 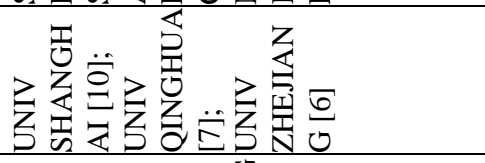 & बे $\bar{\sigma}$ & $\begin{array}{l}\infty \\
1 \\
i \\
0 \\
0 \\
0 \\
0\end{array}$ & 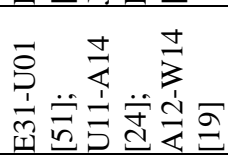 \\
\hline$\underline{1}$ & 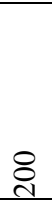 & 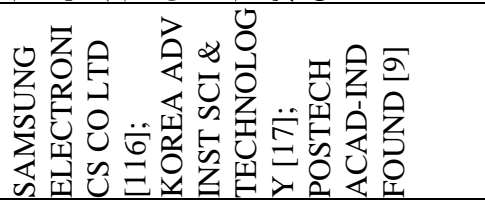 & 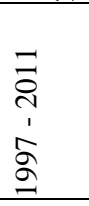 & 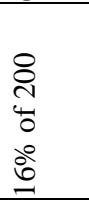 & 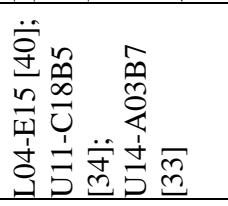 \\
\hline s & $\stackrel{\sim}{\tilde{N}}$ & 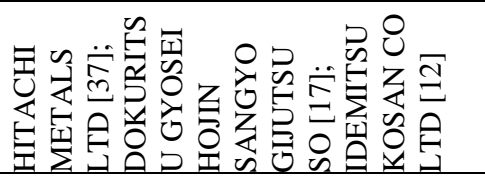 & 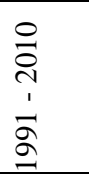 & 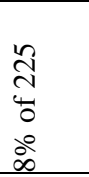 & 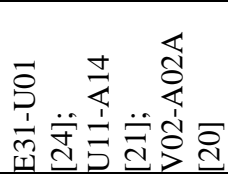 \\
\hline$\tilde{s}$ & $\underset{\mathbb{Z}}{\mathbb{Z}}$ & 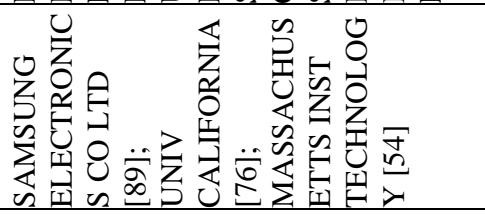 & $\begin{array}{l}\stackrel{0}{0} \\
\stackrel{N}{1} \\
\vdots \\
2 \\
2\end{array}$ & 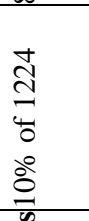 & 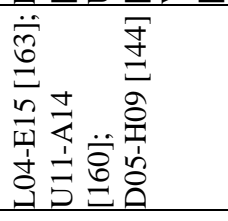 \\
\hline Ü & 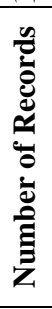 & 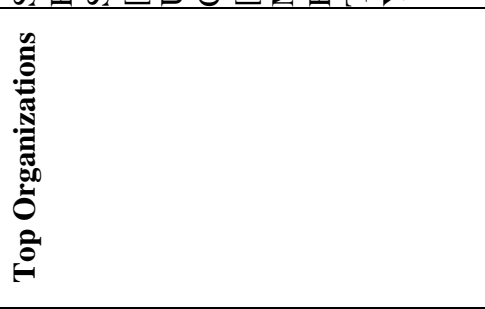 & 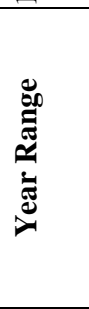 & 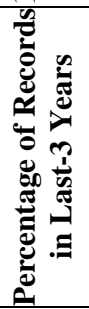 & 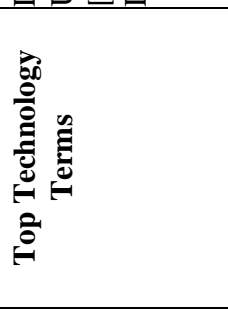 \\
\hline
\end{tabular}

\section{A map of key Nano-crystals technologies and their interconnection}

A Themescape map was generated for the NCs case to see the details of key technology terms that are used in the description of NCs patents. The most used key terms in the themescape analysis appear to be 'gate', 'memory' and 'tunnelling', as shown in Figure 3. The reason why the term 'gate' occurs many times is because organisations involved in NCs technology hope to improve upon existing floating gate technology with a new technology called nanocrystals floating gate flash memory. The term tunnelling is mentioned many times because of the involvement of NCs in making the thin insulating layers used in quantum tunnelling. Regarding flash memory technology, there are two key obstacles that need to be overcome in the future. The first one is the density, which is related to the scaling of the gate length. The length of the gate cannot be reduced after a certain point because when it is reduced there will not be an appropriate gate stack to be controlled by gate-tunnel oxide. Therefore, $\mathrm{NCs}$ floating gate memory requires a different tunnel barrier rather than gate-tunnel oxide. 
Many patents have been issued for methods to solve this problem with various types of tunnel barriers such as Nitride-Oxide-Nitride (NON) and $\mathrm{SiO} 2$. $\mathrm{SiO} 2$ tunnel oxide has the widespread usage due to its great interface properties with $\mathrm{Si}$. Hence, $\mathrm{Si}$ or silicon is mentioned repeatedly and it is linked to the most intense NCs patent terms.

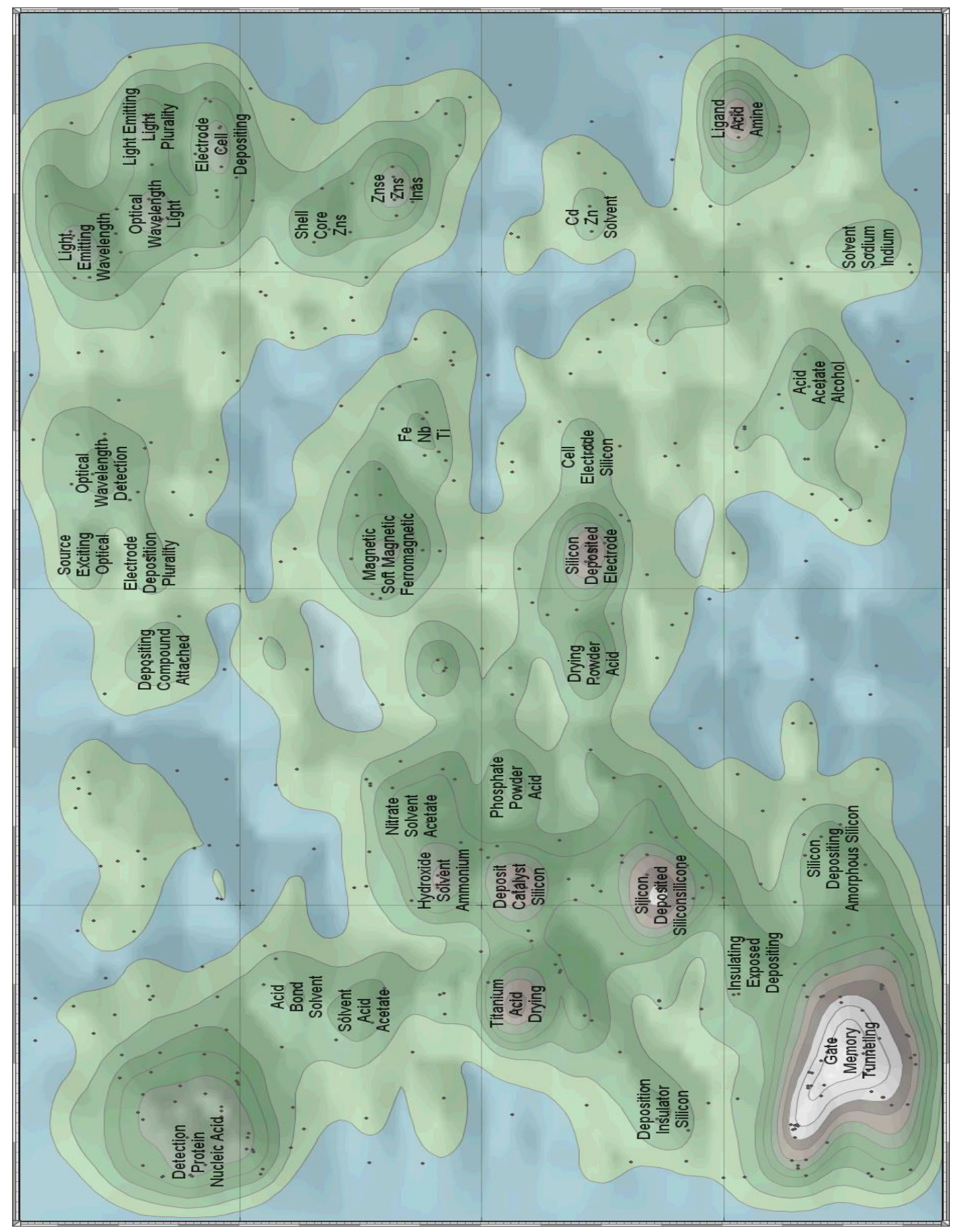

Figure 3: Themescape mapping of Nanocrystals technology and their interconnections

Organisations (industry-academia) involvement and their collaborations in Nano-crystals technology field

The leading organization in NCs technology is Samsung with 118 patent documents. The Korean nanotechnology leader Samsung, as a late mover, was granted its first patent only in 
2001 while most other companies involved in this field became so in the 90s (see Table 3). However, Samsung overtook other companies in the field within quite a short time period. As mentioned before, academic institutions play an important role in NCs technology. Of the top three players, two are US academic organizations: the University of California and Massachusetts Institution Technology. Their successful involvement in this area is very important for the technology diffusion process as academic institutions collaborate with private companies as they try to create spin-offs to commercialize their patents. When looking at the general profile of organizations, the dominant involvement of the electronic industry can be seen, which is, of course, due to the extensive applicability of NCs technology to electronic devices and materials.

Table 3: Profile of organisations in Nano-crystals field

\begin{tabular}{|c|c|c|c|c|c|c|}
\hline$\approx \stackrel{z}{o}$ & 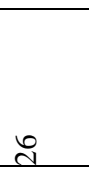 & 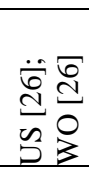 & 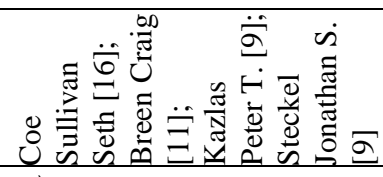 & 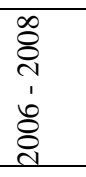 & $\begin{array}{l}\text { i } \\
\text { ते } \\
8 \\
0\end{array}$ & 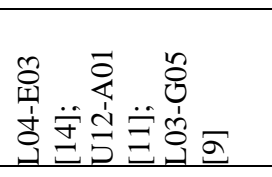 \\
\hline 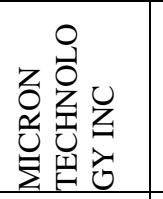 & $\hat{\imath}$ & 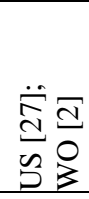 & 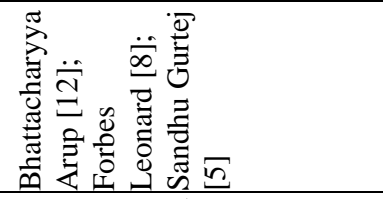 & 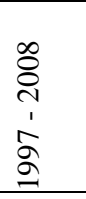 & 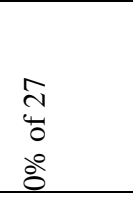 & 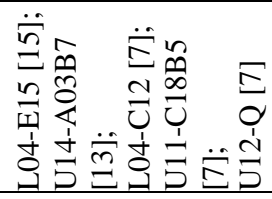 \\
\hline 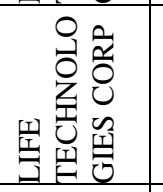 & $\bar{m}$ & 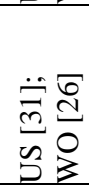 & 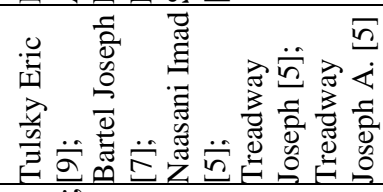 & 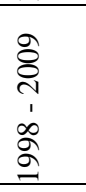 & $\begin{array}{l}\bar{m} \\
\ddot{0} \\
0 \\
\dot{m}\end{array}$ & 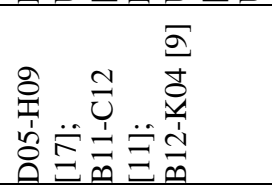 \\
\hline 焉最 & n & 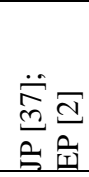 & 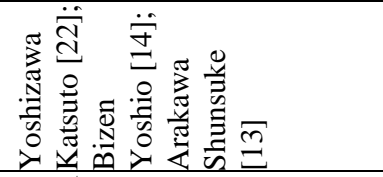 & 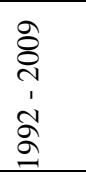 & 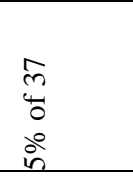 & 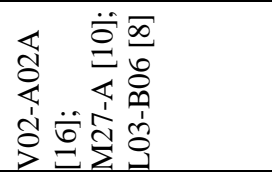 \\
\hline 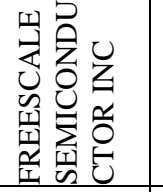 & gf & $\begin{array}{l}\frac{5}{8} \\
s \\
s\end{array}$ & 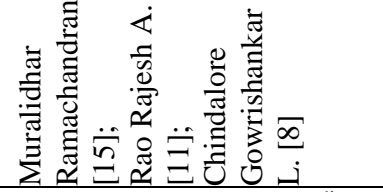 & 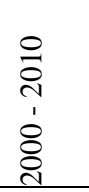 & 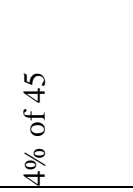 & 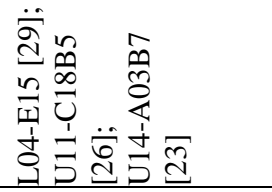 \\
\hline 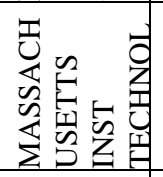 & in & 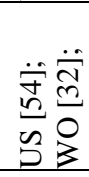 & 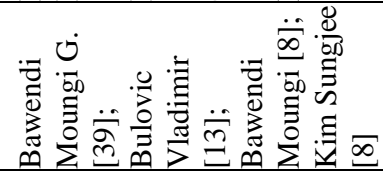 & 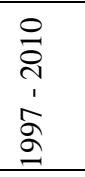 & $\begin{array}{l}n \\
\tilde{n} \\
0 \\
\therefore \\
\therefore\end{array}$ & 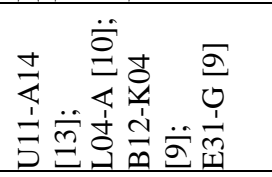 \\
\hline 总突䒴 & 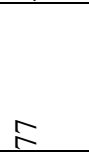 & 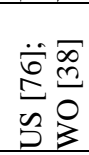 & 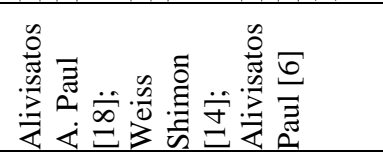 & 응유 & 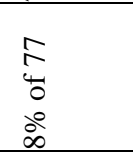 & 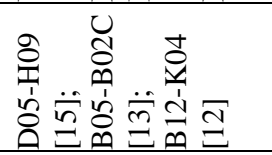 \\
\hline 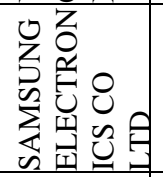 & $\stackrel{\infty}{=}$ & 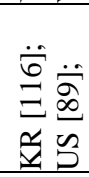 & 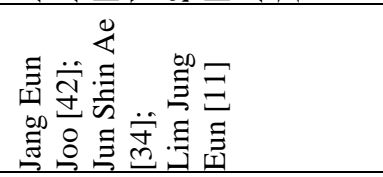 & 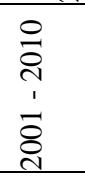 & $\begin{array}{l}\stackrel{\infty}{=} \\
\stackrel{0}{0} \\
\infty \\
\infty\end{array}$ & 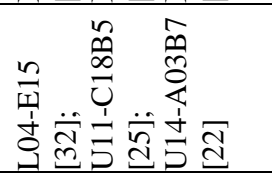 \\
\hline 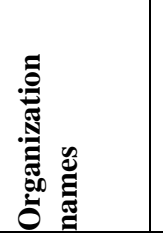 & 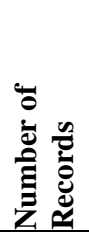 & 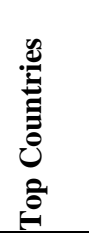 & 苛 & 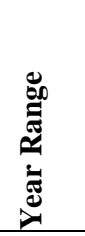 & 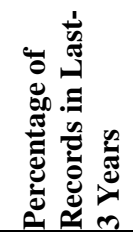 & 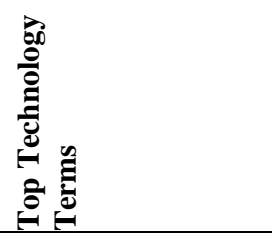 \\
\hline
\end{tabular}

As shown in Table 4, the leading organisations in the NC field are Samsung, University of California, MIT, Freescale Semiconductor and Hitachi Metals. University of California and Hitachi Metals appear to have the longest involvement in $\mathrm{NC}$ related patents. Table $\mathrm{x}$ also shows a notable involvement of academic institutions in $\mathrm{NC}$ technology. For example, the 
University of California appears to be a leading academic player, which strengthens US dominance even further in this area. Moreover, it appears that there is a great collaboration between MIT and University of California that strengthens their position in this field. Another significant collaboration mechanism is between Samsung and other Korean based institutions. These academic institutions' involvement and their collaborations may positively affect the commercialisation process in view of their high number of granted patents and their role within technology transfer activity networks.

Table 4: Key organisations and their collaborations in Nano-crystals

\begin{tabular}{|c|c|c|c|}
\hline $\begin{array}{l}\text { Number } \\
\text { of Patents }\end{array}$ & Organization Names & $\begin{array}{l}\text { Top Collaborating } \\
\text { Organizations }\end{array}$ & $\begin{array}{l}\text { Year } \\
\text { Range }\end{array}$ \\
\hline 118 & $\begin{array}{l}\text { SAMSUNG } \\
\text { ELECTRONICS CO LTD }\end{array}$ & $\begin{array}{l}\text { IUCF-HYU [3]; } \\
\text { SNU R\&DB FOUND [2]; } \\
\text { UNIV HANYANG IND COOP } \\
\text { FOUND [2] }\end{array}$ & $2001-2010$ \\
\hline 77 & UNIV CALIFORNIA & $\begin{array}{l}\text { LOS ALAMOS NAT } \\
\text { SECURITY LLC [4]; } \\
\text { MASSACHUSETTS INST } \\
\text { TECHNOLOGY [2] }\end{array}$ & $1990-2010$ \\
\hline 55 & $\begin{array}{l}\text { MASSACHUSETTS INST } \\
\text { TECHNOLOGY }\end{array}$ & UNIV CALIFORNIA [2] & $1997-2010$ \\
\hline 45 & $\begin{array}{l}\text { FREESCALE } \\
\text { SEMICONDUCTOR INC }\end{array}$ & MOTOROLA INC [3] & $2000-2010$ \\
\hline 37 & HITACHI METALS LTD & None & $1992-2009$ \\
\hline
\end{tabular}

\section{Industry-Academia linkages in Nano-crystals technology field}

Looking at the linkage types between organisations in Figure 4, five clusters have been identified.

Cluster 1 shows some evidences of mono-linkages between organisations. The thickness of the linkage presents the significance of linkages between organisations. Generally, it can be said that mono-linkages between organisations result in stronger collaborations in patenting activities. As an example, Hon Hai Precision (Foxconn) and Qinghua (Tsinghua) University appear to have a highly strong linkage among them. This is due to their patent agreement within nanotechnology field that both parties share their IP rights and there is an established TsinghuaFoxconn Nanotechnology Center where both parties have active roles to commercialise nanotechnology related products.

Looking at the cluster 2 and 3, it can be seen that the US Navy appears to have the highest number of linkages with 10 collaborations, 8 of which are with US based academic organisations. One of their international linkages is with an Israeli institution, the Yissum Research Development Company of the Hebrew University of Jerusalem. The aim of this technology transfer process is to protect and commercialize the Hebrew University's intellectual property. US Secretary of Navy also collaborates with the Chinese based Shanghai Jiaotong University. 


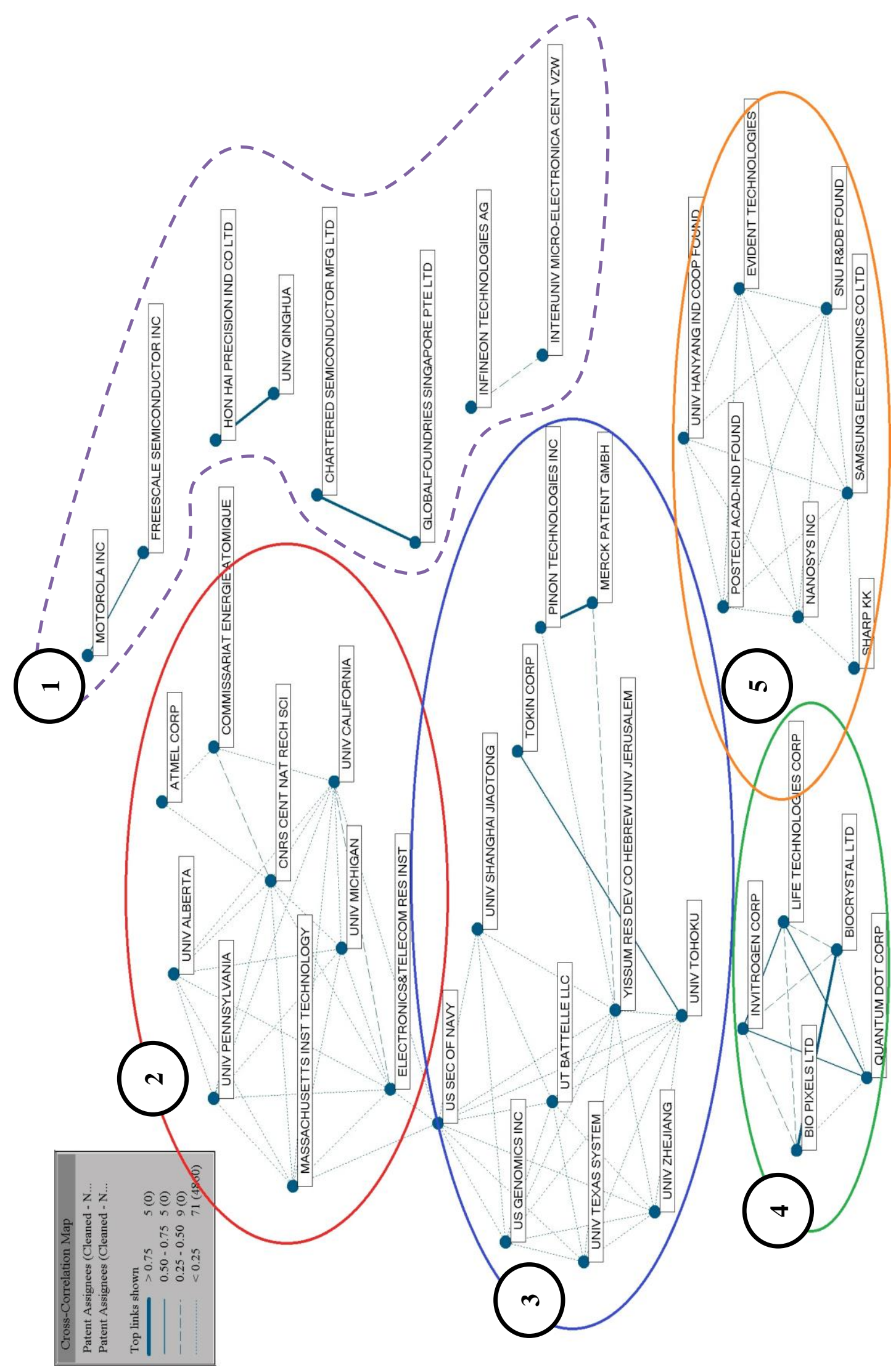

Figure 4: Industry-academia linkages in Nano-crystals technology field 
As appears in the linkage map of the nano-crystals field, US based academic organisations appear to have linkage with French institutions such as CNRS. Looking at the cluster 2 and 3, it can be seen the academic organisations in the US have the strongest linkage with almost 20 linkages with other organisations within the NC field. Cluster 2 and 3 has highly decentralised linkage between organisations. Another strong linkage is between the US based cooperating organisations as shown by cluster 4 . An interesting point is that all members of this linkage (cluster 4) are highly focused on NCs and quantum dot technology, and their research focus is not very dispersed. Cluster 4 appears to have oligo-linkage type where the network appears to be expending. These kinds of linkages may indicate a focused research group as there are no high number of linkages with players from different sectors.

The cluster 5 has a Korean dominance but it is a highly international linkage that involves Korea, Japan and the US. This cluster shows an international small decentralized-linkage as there is no clear dominant player even though Samsung's involvement. Evident Technologies is a US based nanotechnology company that is focused on the commercialization of quantum dot semiconductor nanocrystals. Evident Technologies was the first company in the world to commercialize quantum dot LEDs with products launched in 2007. In 2011, Samsung and Evident Technologies had an agreement in patent licensing and purchasing for Evident's quantum dot LED technology. This agreement grants Samsung worldwide access to Evident's patent portfolio for all products related to quantum dot LEDs from manufacture of the quantum dot nanomaterials to final LED production. Quantum dots are nanometer-sized semiconductor crystals that have great commercial promise in electronic applications from solar energy conversion to thermoelectrics to LEDs. Samsung also has collaborations with Korean based organisations such as Industry-University Cooperation Foundation of Hanyang University and Postech Academy Industry Foundation. Other key players in this linkage are Nanosys with Japanese Sharp Corporation which are working together to develop nanotechnology enabled fuel cells. According to the terms of the agreement, Sharp will finance the cooperative development activities to discover high performance fuel cells for use in portable consumer electronics such as laptop computers, mobile phones, and multimedia devices.

\section{DISCUSSION AND IMPLICATIONS}

This research offers an innovative look at various relationships within nanocrystals field with a visual mapping, clustering and tech mining methods to gather various determinants to understand this field better. The analysis of NCs patenting activity presented academic and industrial linkage mechanism in this field. Organisational profiles of the NCs field presented the leading academic and corporate organisations and the results are very different to those of other studies that have been conducted in this field. Asian based Companies involvement has turned out to be very successful as Samsung has become the leading organisation. The analysis of the nanocrystals-patenting network presented novel results. It presented different clusters at national and international level; how these clusters are linked and how academic and industrial organisations are linked to each other. Some nations such as Korea and Japan presented highly collaborative clusters. The US also had a linked cluster but two dissimilarities in comparison with other nations. Firstly they had a higher level of international linkages, for example with France, Korea, Taiwan, China and Japan and secondly, the academic institutions appear to have a stronger relationship amongst each other. China presented a great illustration of an effective linkage in patenting activity and co-inventorship between academic and corporative organisations. It was found that the strongest linkage is between Hon Hai Precision (known as Foxconn) and Qinghua University (known as Tsinghua University), which were supported by their establishment of the Tsinghua-Foxconn Nanotechnology Research Center.

The analysis on the technological trends of nanocrystals is very useful as it gives the key information nanocrystal technology cluster. By using the Themescape tool, specific nanotechnology related terms were analysed to see their linkage, their intensity and their various usages. For example, the Themescape for NCs was a more specific analysis that 
presented the details of a nanostructure in terms of its usage, its various elements and its benefits. Nanocrystalline semiconductor materials can be used in flash memories that have a wide usage in many electronic devices such as pen drives, memory sticks, MP3 players, PDAs and hybrid hard disks. The significance of NCs in semiconductor memories is that this kind of nanomaterial can scale down the switching circuit areas as the thickness of $\mathrm{SiO} 2$ layers cannot be reduced any further. The present floating gate technology can be replaced with NCs so miniaturized that highly reliable flash memories can be produced. This offering of NCs became one of the most attractive areas in the nanotechnology field for many organizations that with interests in the electronics industry. The usage of NCs in polymer applications attracts most attention from companies within the hybrid polymer NC photovoltaic (PV) cells. This technology has a high potential to enable low cost solar energy devices to be produced with great power conversion efficiency. Hybrid polymer NCs PV devices are a promising technology for the application of hybrid materials in electronic devices, and the electronic properties of colloidal inorganic NCs are highly advantageous compared to other materials that are used today, so NCs should have a high rate of commercialisability in the near future

Through the case of NCs study, it was seen that over $82 \%$ of patent documents were granted to organisations that own less than 20 nanocrystal patents so there was not a distinctive dominance but there were four central clusters. Interestingly, US Navy had the highest number of collaborations and there were international connections with Israeli and Chinese organisations. This was not an expected collaboration by considering US Navy's strategic condition. In the NCs case the strongest network appeared to be the Japanese patenting network but the strongest cluster appeared to be the US patenting network. Accordingly, it can be said that NCs field has different dominant actors and different dominant countries that depends on the technology domain in the field. Another important gathering from this case is that the level of international linkage between organisations was not dramatically reduced when the number of available of NCs field is considered.

Proposed model is tested with the NC patenting network. Results presented different type of linkage mechanisms as proposed and there were no any central-linkage where there are clear dominant players. Most of linkages were highly decentralized and this can be considered as a positive sign considering the stability of the network. In general, it is found that linkages between organisations are stronger when there are mono-linkages. In Foxconn-Tsinghua case it is found that this is due to special agreements and strong establishments such TsinghuaFoxconn Nanotechnology Center. However, these kinds of linkages appear less supportive in terms technology diffusion as it does not allow other parties to benefit from technological outcomes.

The implication of this study is that patent data analysis provides a great tool that enables active and potential participants in this field to gain from:

- Knowledge of changing trends in the case of nanocrystals at country and organisational level, for example the changing role of Asian countries and the increasing importance of Korean organisations

- Linkage mechanism within NCs field appears to be highly decentralized and that there is little number of dominant players. Mono-linkages result in stronger linkages between parties.

- The linkages between national innovation systems at the international level that presents which companies collaborate with each other and which organisations or organisation groups play a key role in this aspect

There are many other relationships that can be looked at with nanotechnology patent analysis. Future studies could look at different technology domains and their relationships with each other at the country level and international level. This empirical study could be taken to a qualitative level by analysing the technology claims and abstracts of each patent to see how a specific sub-nanotechnology category linked with industry. 


\section{REFERENCES}

[1] Linton, J. and S. Walsh, Acceleration and extension of opportunity recognition for nanotechnologies and other emerging technologies, International Small Business Journal. Vol. 26(1), 83-99, 2008.

[2] Libaers D., M. Meyer, A. Geuna, The Role of University Spinout Companies in an Emerging Technology: The Case of Nanotechnology, The Journal of Technology Transfer, Vol. 31(4), 443450, 2006.

[3] Islam, N. and N. Ekekwe, Disruptive Technologies, Innovation and Global Redesign, in Disruptive Technologies, Innovation and Global Redesign: Emerging Implications, Ekekwe, N. and Islam, N., Ed. IGI Global: PA, USA, 2012.

[4] Islam N. and K. Miyazaki, An empirical analysis of nanotechnology research domains. Technovation, Vol. 30(4), 229-237, 2010.

[5] Shea C.M.; Future management research directions in nanotechnology: A case study. Journal of Engineering and Technology Management, Vol. 22 (3), 185-200, 2005.

[6] Guellec, D. and B.P. Potterie, The internationalisation of technology analysed with patent data, Research Policy, Vol. 30 (8), 1253-1266, 2001.

[7] David, P.A., B.H. Hall and A.A. Toole, Is public R\&D a complement or substitute for private R\&D? A review of the econometric evidence, Research Policy, Vol. 29 (4-5), 497-529, 2000.

[8] Malo, S.; The contribution of (not so) public research to commercial innovations in the field of combinatorial chemistry, Research Policy, Vol. 38 (6), 957-970, 2009.

[9] Liu, C.; Government's role in developing a high-tech industry: the case of Taiwan's semiconductor industry, Technovation, Vol. 13 (5), 299-309, 1993.

[10]Feldman, M.P. and M.R. Kelley, The ex-ante assessment of knowledge spillovers: Government R\&D policy, economic incentives and private firm behavior, Research Policy, Vol. 35 (10), 1509$1521,2006$.

[11]Dangelico, R.M., A.C. Garavelli and A.M. Petruzzelli, A system dynamics model to analyze technology districts' evolution in a knowledge-based perspective, Technovation, Vol. 30 (2), 142$153,2010$.

[12] Crespi, G., P. D'Este, R. Fontana and A. Geuna, The impact of academic patenting on university research and its transfer, Research Policy, Vol. 40 (1), 55-68, 2011.

[13] Senker, J.; National systems of innovation, organizational learning and industrial biotechnology, Technovation, Vol. 16 (5), 219-229, 1996.

[14]Liu, X. and S. White, Comparing innovation systems: a framework and application to China's transitional context, Research Policy, Vol. 30 (7), 1091-1114, 2001.

[15] Collins K.M.T., A.J. Onwuegbuzie and Q.G. Jiao, A mixed methods investigation of mixed methods sampling designs in social and health science research. Journal of Mixed Methods Research, Vol. 1, 267-294, 2007.

[16] Nelson, A.J.; Measuring knowledge spillovers: What patents, licenses and publications reveal about innovation diffusion, Research Policy, Vol. 38 (6), 994-1005, 2009.

[17] Baldini, N., R. Grimaldi, and M. Sobrero, Institutional changes and the commercialization of academic knowledge: A study of Italian universities' patenting activities between 1965 and 2002, Research Policy, 35 (4), 518-532, 2006.

[18] Fontana, R., A. Geuna and M. Matt, Factors affecting university-industry R\&amp;D projects: The importance of searching, screening and signalling, Research Policy, Vol. 35 (2), 309-323, 2006.

[19] Kang, K.N. and H. Park, Influence of government R\&D support and inter-firm collaborations on innovation in Korean biotechnology SMEs, Technovation, Vol. 32 (1), 68-78, 2012.

[20] Sorek, G.; Patents and quality growth in OLG economy, Journal of Macroeconomics, Vol. 33 (4), 690-699, 2011.

[21] Greif, S.; Patents and sectors of economy. Connection between the international patent classification and the systematics of the sectors of economy, World Patent Information, Vol. 14 (4), 245-249, 1992.

[22] Abraham, B.P. and S.D. Moitra, Innovation assessment through patent analysis, Technovation, Vol. 21 (4), 245-252, 2001.

[23] $\mathrm{Wu}$, Y.J. and Pi-Ju Lee, The use of patent analysis in assessing ITS innovations: US, Europe and Japan, Transportation Research Part A: Policy and Practice, Vol. 41 (6), 568-586, 2007.

[24] Encaoua, D., D. Guellec and C. Martínez, Patent systems for encouraging innovation: Lessons from economic analysis, Research Policy, Vol. 35 (9), 1423-1440, 2006.

[25] Faber, J. And A.B. Hesen, Innovation capabilities of European nations: Cross-national analyses of 
patents and sales of product innovations, Research Policy, Vol. 33 (2), 193-207, 2004.

[26] Bachmann, A.; Profiles of corporate technological capabilities — a comparison of large British and German pharmaceutical companies, Technovation, Vol. 18 (10), 593-604, 1998.

[27] Trappey, C.V., H.Y. Wu, F.T. Dutta and A.J.C. Trappey, Using patent data for technology forecasting: China RFID patent analysis, Advanced Engineering Informatics, Vol. 25 (1), 53-64, 2011.

[28] Tseng, F.M., C.H. Hsieh, Y.N. Peng and Y.W. Chu, Using patent data to analyze trends and the technological strategies of the amorphous silicon thin-film solar cell industry, Technological Forecasting and Social Change, Vol. 78 (2), 332-345, 2011.

[29] Lundvall, B.; National Systems of Innovation: Towards a Theory of Innovation and Interactive Learning, London: Pinter, 1992.

[30] Freeman, C.; The National System of Innovation in Historical Perspective, Cambridge Journal of Economics, Vol. 19, 5-24, 1995.

[31] Nelson, R.; National Innovation Systems, Oxford: Oxford University Press, 1993.

[32] Cooke, P. and K. Morgan, The Creative Milieu: a Regional Perspective on Innovation, in M. Dodgson, et al Ed., The Handbook of Industrial Innovation, 57-89, 1994.

[33] Cooke, P. and K. Morgan, The Associational Economy: Firms, Regions and Innovation, Oxford: Oxford University Press, 1998.

[34] Malerba, F.; Sectoral Systems of Innovation: Concepts, Issues and Analyses of Six Major Sectors in Europe, Cambridge: Cambridge University Press, 2004.

[35] Carlson, B. and R. Stankiewicz, On the nature, function and composition of technological systems, Journal of Evolutionary Economics, Vol. 1, 93-118, 1991.

[36] Johnson, A.; Functions in innovation system approaches, Department of Industrial Dynamics, Chalmers University of Technology, 1998.

[37] OECD, National Innovation System, Paris: OECD, 1997

[38] Leydesdorff, L. and M. Meyer, The Triple Helix of university - industry - government relations. Scientometrics, Vol. 58(2), 191-203, 2003.

[39] Bell, G. and M. Callon, Techno-Economic Networks and Science and Technology Policy, STI Review, 14, 59-118, OECD, 1994.

[40] Paudyal, D.R., K. McDougall and A. Apan, A Regional Collaborative Network to Improve Spatial Information Sharing in Australia, 12th Global Spatial Data Infrastructure Association World Conference, Singapore, 2010.

[41] Porter, A.L. and S.W. Cunningham, Tech mining: exploiting new technologies for competitive advantage. New Jersey: John Wiley and Sons, 2005. 